\title{
REACTIVITY STUDIES OF MALEIMIDE EPOXY RESIN WITH LONG CHAINED AMINES
}

\author{
LAKSHMI.B ${ }^{I}$ SHIVANANDA.K.N $2^{*}$ AND MAHENDRA.K.N..$^{*}$ \\ ${ }^{\prime}$ Department of Studies in Chemistry, Central College Campus, Bangalore University, \\ Bangalore-560001, India \\ ${ }^{2}$ Schulich Faculty of Chemistry, Technion - Israel Institute of Technology, Technion City, Haifa -32000, Israel
}

(Received: October 26, 2009 - Accepted: July 1, 2011)

\begin{abstract}
After phenylmaleimido group was successfully incorporated into bisphenol-A type epoxy resins (B-13) to result in compound possessing both oxirane ring and maleimide reactive groups. The cured maleimide epoxy samples are obtained by thermally curing of the maleimide epoxy (MIE) compounds with aliphatic long chained amines such as Tetraethylenepentamine (TEPA), Bishexamethylenetriamine (BHMT), 2-methyl pentamethylenediamine (2-MPMDA) and 2,2,4-trimethy diamines (2,2,4-TMDA) exhibited excellent thermal stability and good chemical (acid/alkali/solvent) and water absorption resistance. Morphological studies by the SEM technique further confirmed the phase homogeneity net work of the cured systems.
\end{abstract}

Key words: Amine, Epoxy resin, Malemide, Curing, and Epichlorohydrin.

\section{INTRODUCTION}

Epoxy resins are widely used in industrial applications owing to their many attractive properties, such as excellent chemical and solvent resistance, good thermal and electrical properties ${ }^{1}$. At present epoxy resins are extensively used in various technical applications such as coatings, composites and as structural adhesives ${ }^{2}$. The use of epoxy resin in high performance structural materials has been increasing recently. There is a lot of scope and need for improving the properties of epoxy resins to be used in advanced applications. For example, epoxy resin with superior thermal stability is needed for using as molding compounds and encapsulation materials in advanced electronic components. Generally, modifying epoxy resin with polyamides or imido compounds $\mathrm{s}^{2-3}$ provide a convenient approach of enhancing the thermal stability of epoxy resins. Therefore, epoxy resins were cured with reactive polyimides ${ }^{2-4}$, polyamic acid $^{5}$, and imido-modified curing agents ${ }^{6}$ to introduce imide structure into epoxy resin. The thermal stability of the above mentioned imido epoxy resins was significantly leveled up both in the initial decomposition temperature (IDT) and the integral procedural decomposition temperature (IPDT) ${ }^{7}$.

On the other hand, epoxy resins modified with maleimide compounds also received attractive attentions, due to the similar curing conditions and processing properties of the epoxy resins and maleimides. Maleimide-epoxy resins usually showed appropriate properties between epoxy and maleimide resins. Thus, both the intercrossed and the interpenetrating systems (IPN) based on bismaleimides and epoxy resins were prepared and exhibited good thermal and mechanical properties Additionally, since imide groups could provide char formation in the condensed phase to improve polymers flame retardant properties, epoxy resins modified with imide compounds through chemical reactions or physical blending have been reported to show good flame retardant properties. ${ }^{8-12}$

In the continuation of privies ${ }^{14-15}$ work the maleimide epoxy compounds were consequently obtained through a simple addition reaction between the oxirane ring of epoxy compounds and hydroxyl group of maleimide. The resulting maleimide epoxy compounds possessed both oxirane ring and maleimide reactive groups. Each of the reactive groups might form crosslinking networks under thermal curing reaction with curing agents such as Tetraethylenepentamine (TEPA), Bishexamethylenetriamine (BHMT), 2-methyl pentamethylenediamine (2-MPMDA) and 2,2,4-trimethy diamines $(2,2,4-$ TMDA $)$ to bring about high cross-linking density. So it was considered worthwhile to study the synthesis, characterization and curing reaction of the maleimide epoxy compounds with different long chain amines and to study the properties of the cured resin systems (For water absorption resistance and chemical resistance properties).

\section{EXPERIMENTAL}

Materials and Measurements :Maleic anhydride and 4-aminophenol were purchased from S.d.Fine chemicals. The following bisphenol-A based epoxy resins were used. (Lapox* make supplied by ATUL Ltd, polymer division); Lapox B-13 (High viscous liquid; Viscosity at $25^{\circ} \mathrm{C}, 12000-16000$ $\mathrm{m}$ pas). Tetraethylenepentamine (TEPA), Bishexamethylenetriamine (BHMT), 2-methyl pentamethylenediamine (2-MPMDA) and 2,2,4-trimethy diamines (2,2,4-TMDA) supplied by Merck and Aldrich chemicals were used as such. Triphenylphosphine (TPP), Dimethylformamide (DMF) and Toluene were obtained from Aldrich chemicals.

Infrared spectra were recorded using Nicolet FT-IR spectrometer using $\mathrm{KBr}$. Elemental analyses were carried out in Liquid Crystal Department, Raman Research Institute, Bangalore. The ${ }^{1} \mathrm{H}$ NMR spectra of MIE compound is recorded in Sophisticated Instrument Facility, Indian Institute of Science, Bangalore. TGA/DTA for cured samples is recorded in National Chemical Laboratory, Pune.

Synthesis of N-(hydroxyphenyl) maleamic acid (HPMAc): Synthesis of MIE has been followed according literature ${ }^{14-15}$.

In a 2-necked flask equipped with a mechanical stirrer and a reflux condenser, maleic anhydride $(0.88 \mathrm{~mol}, 86.4 \mathrm{~g})$ dissolved in $700 \mathrm{ml}$ acetone was charged. The solution was stirred at ambient temperature, and 4-aminophenol $(0.80 \mathrm{~mol}, 87.2 \mathrm{~g})$ was added in portions over $30 \mathrm{~min}$. The reaction mixture turned into yellow slurry. After stirring for $1.5 \mathrm{~h}$ the slurry was filtered. The solid was washed with acetone, and then dried at $60^{\circ} \mathrm{C}$ under vacuum to give light green powder product. Yield $95 \%$. Molecular Formula: $\mathrm{C}_{10} \mathrm{H}_{9} \mathrm{NO}_{4}$. Elemental analysis: Found \%(Calcd \%)C:57.90(57.97), H:4.38(4.35),N:6.80(6.76). IR( $\left.\mathrm{KBr}, \mathrm{cm}^{-1}\right)$ : $3312(\mathrm{~N}-\mathrm{H}), 3200(\mathrm{O}-\mathrm{H}), 1703(-\mathrm{COOH}), 1621(\mathrm{C}=\mathrm{O})$ and $1600(\mathrm{C}=\mathrm{C})$.

Synthesis of N-(4-hydroxy phenyl) maleimide (HPM): In a 3-necked flask equipped with a mechanical stirrer, water segregation, and a reflux condenser, HPMAc $(0.6 \mathrm{~mol}, 123.2 \mathrm{~g})$, p-toluenesulphonic acid $(0.05 \mathrm{~mol}$ $8.75 \mathrm{~g})$, dimethylformamide $(60 \mathrm{ml})$ and toluene $(700 \mathrm{ml})$ were charged. The mixture was heated to reflux for about $8-10 \mathrm{~h}$ until the slurry turned into a clear solution and the stoichiometric amount of water was segregated. After removing toluene, the residue was poured into a large amount of water. The precipitate was collected with filtration, washed with $5 \%$ sodium bicarbonate solution, and with water. The crude product was recrystallized from a mixed solvent of water-isopropanol $(1: 1)$ to give brown crystalline needle product. Yield:64\%.Molecular formula $\mathrm{C}_{10} \mathrm{H}_{7} \mathrm{NO}_{3}$. Elemental analysis: Found \%(Calcd \%) C:63.50(63.49), H:3.66(3.70),N:7.45(7.41). IR $\left(\mathrm{KBr}, \mathrm{cm}^{-1}\right): 3416(\mathrm{O}-\mathrm{H})$, $1709(-\mathrm{C}=\mathrm{O}), 1641(\mathrm{C}=\mathrm{C})$, and $1388(\mathrm{C}-\mathrm{N})$.

Synthesis of maleimide epoxy compounds (MIE) : MIE was prepared by reacting B-13 epoxy resin and N-(4-hydroxy phenyl) maleimide (HPM). HPM $(0.027 \mathrm{~mol}, 3.74 \mathrm{~g})$ and B-13/B-11(12.53g) were dissolved in $20 \mathrm{ml}$ of methylethylketone in a $150 \mathrm{ml}$ round bottomed flask. TPP $(0.05 \mathrm{~g})$ was added to the solution as a reaction promoter. The reaction solution was then heated to reflux (at about $130-140^{\circ} \mathrm{C}$ or $4 \mathrm{~h}$ and then cooled at room temperature. The solvent was removed out with rotary evaporator. The product was then heated at $70^{\circ} \mathrm{C}$ under vacuum for $6 \mathrm{~h}$ to give a semisolid product ${ }^{14}$. Yield $90 \%$. Elemental analysis: Found \%(Calcd \%)C: 69.21(69.87), H:5.80(5.72),N:2.88(2.96). $\mathrm{IR}\left(\mathrm{KBr}, \mathrm{cm}^{-1}\right): 3471(\mathrm{O}-\mathrm{H}), 1636(\mathrm{C}=\mathrm{O}), 1638(\mathrm{C}=\mathrm{C}), 1367(\mathrm{C}-\mathrm{N})$, and 917 (oxirane ring). ${ }^{1} \mathrm{H}$ NMR (ppm, in DMSO-d $\left.{ }_{6}\right): 1.54$ (s,6H), 2.64-2.66 (t, 1.2H), 2.77-2.81 
$(\mathrm{t}, 1.2 \mathrm{H}), \quad 3.25-3.28(\mathrm{~m}, 1.2 \mathrm{H}), \quad 3.43(\mathrm{~m}, 0.8 \mathrm{H}), 3.71-3.77(\mathrm{~m}, 1.2 \mathrm{H}), 3.95(\mathrm{~b}, 3.2 \mathrm{H} 0$ $4.20-4.25(\mathrm{~m}, 1.2 \mathrm{H}), 5.39(\mathrm{~b}, 0.8 \mathrm{H}), 6.71-7.29(\mathrm{~m}, 12.8 \mathrm{H})$. Softening point:110$112^{\circ} \mathrm{C}$. Epoxy equivalent weight (MIEB-13) $=451$ (calculated value 445).

Preparation of Cured Epoxy Resins: The cured epoxy resins were obtained from thermally curing of maleimide epoxy resin (MIE) with amines such as tetraethylenepentamine (TEPA), bishexamethylenetriamine (BHMT), 2-methyl pentamethylenediamine (2-MPMDA) and 2,2,4-trimethy diamines (2,2,4-TMDA) as curing agents. Stoichiometric amounts of MIE and curing agents (based on hydrogen equivalent weight) were mixed together in methylethylketone solution and cured in oven. The conditions of curing reactions for B-13MIE/ TEPA, B-13MIE/ BHMT, B-13MIE/2-MPMDA, and B-13MIE/ 2,2,4-TMDA compositions were $60^{\circ} \mathrm{C}(24 \mathrm{~h})$.

\section{RESULTS AND DISCUSSION}

Preparation of MIE epoxy compounds: The sequence of reactions involved in the synthesis of MIE is shown in Scheme 1. The preparation of the maleimide-epoxy compounds (MIE) were performed by reacting HPM with a diglycidylether of bisphenol-A (B-13) via addition reactions between the phenol group and the oxirane group (Scheme 1). Owing to the high viscosity of the resulting products, a solution process was carried out for the above mentioned reactions with $500 \mathrm{ppm}$ of triphenylphosphine as a catalyst and methylethylketone as a solvent.
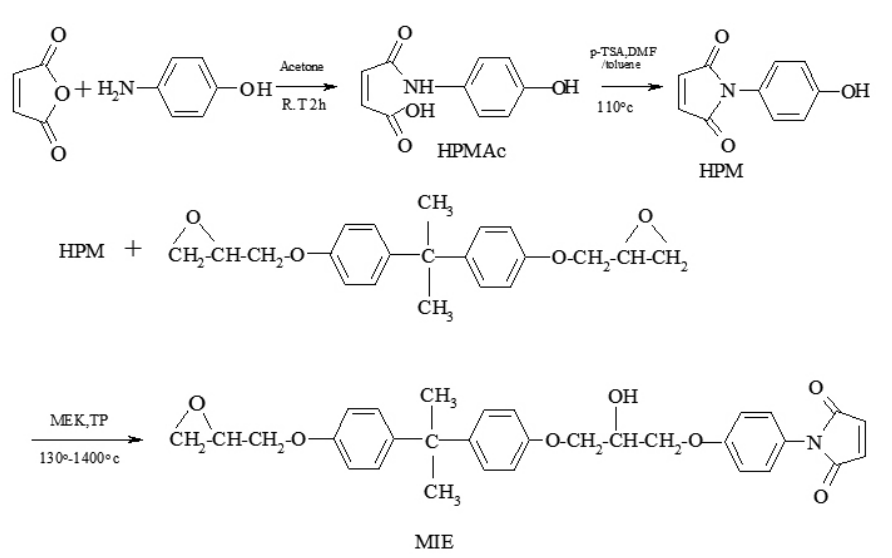

Scheme 1: Preparation of maleimide epoxy compound.

The epoxy equivalent weight values of the maleimide-epoxy compounds calculated from reaction compositions were consistent with the values obtained from titration experiments. This result implies the high conversions of the reactions between phenol groups and oxirane rings. The above reaction was monitored by FT-IR ${ }^{14-15}$. The decrease in the intensity of the absorption peak of the oxirane ring at $917 \mathrm{~cm}^{-1}$ clearly indicated the decrease in concentration of oxirane rings as the reaction proceeds. The chemical structure of the resulting maleimide epoxy compound obtained was confirmed by the presence of the following absorption peaks at $1367 \mathrm{~cm}^{-1}(\mathrm{C}-\mathrm{N}), 1711,1778$ and 716 (imide group), and $1698 \mathrm{~cm}^{-1}(\mathrm{C}=\mathrm{C})$. The authenticity of maleimide epoxy compounds was also confirmed by the elemental analysis. The maleimide epoxy compounds obtained were highly viscous liquid, and this may be due to incorporation of the heterocyclic hard imido-phenyl groups, and increase of molecular weight.

In addition to IR and elemental analysis, ${ }^{1} \mathrm{H}$ NMR analysis on the MIE compound also indicated the proposed chemical structure (scheme 1). The appearance of the absorption peaks at about $3.95 \mathrm{ppm}$ (ring opened oxirane ring,- $\mathrm{OCH}_{2} \mathrm{CH}(\mathrm{OH})-$ ) and $5.39 \mathrm{ppm}(-\mathrm{COH})$ demonstrated the performance of the addition reaction between HPM and B-11/B-13. The peaks at about $2.64,2.77,3.25,3.75$ and $4.24 \mathrm{ppm}$ showed the typical oxirane absorptions, and the peak at $1.54 \mathrm{ppm}$ exhibited the absorption of the isopropyl group. Moreover, the HPM/B-13 unit ratios were directly calculated from the peak area ratios of the absorption at 6.71-7.29 ppm (aromatic proton and $\mathrm{CH}=\mathrm{CH}$ ), and the absorption peak at $1.54 \mathrm{ppm}$ (isopropyl group), and the results were coincident with the feeding ratios of HPM/B-13 for every MIE compounds. Additionally, the chemical structures of MIE compounds were confirmed with the experimental results of elemental analysis.

Curing reactions of MIE with amines: The curing reactions were carried out with different stoichiometric ratios of the above resins(MIE) on a aluminum foil boat of $10 \mathrm{~cm}$ diameter. To this different amines such as Tetraethylenepentamine (TEPA), Bishexamethylenetriamine (BHMT), 2-methyl pentamethylenediamine (2-MPMDA) and 2,2,4-trimethy diamines(2,2,4-TMDA) based on their hydrogen equivalent weights are added and mixed thoroughly for a minute using thin wooden stick. In all cases the temperature of the reaction mixture at different intervals of the time are measured using a infrared gun and the completion of the curing is indicated when the reaction mixture becomes nonsticky with a wooden stick. The epoxide groups in epoxy resin react with the amine to form a highly crosslinked, three dimensional network. The curing process converts the epoxy resins into a hard, infusible and rigid material. All the curing reactions were carried out at $60^{\circ} \mathrm{C} 24$ hours. The mechanism of curing reaction has been in scheme 2 and 3 . The reactivity studies of MIEB-13 compound with different amines are shown in the Fig 1 .

$$
\begin{aligned}
& -\overbrace{\mathrm{CH}_{2}-\mathrm{NH}_{2}+\mathrm{CH}_{2}-\mathrm{CH}_{-}-\mathrm{CH}_{2}-\mathrm{O}-\mathrm{C}_{6} \mathrm{H}_{6}-\longrightarrow} \longrightarrow-\mathrm{CH}_{2}-\mathrm{NH}-\mathrm{CH}_{2}-\mathrm{CH}_{-}-\mathrm{CH}_{2}-\mathrm{O}-\mathrm{C}_{6} \mathrm{H}_{6}-
\end{aligned}
$$

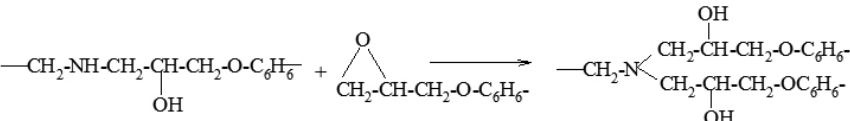

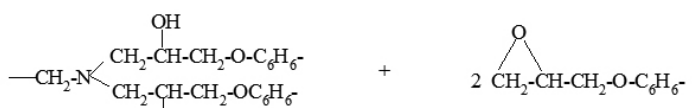

$$
\begin{aligned}
& \mathrm{OH} \\
& \downarrow \\
& \begin{array}{c}
\mathrm{OH} \\
\mathrm{O}-\mathrm{CH}_{2}-\mathrm{CH}_{-}-\mathrm{CH}_{2}-\mathrm{O}-\mathrm{C}_{6} \mathrm{H}_{6}- \\
-\mathrm{CH}_{2}-\mathrm{NK}^{\mathrm{N}} \mathrm{CH}_{2}-\mathrm{CH}_{2}-\mathrm{CH}_{2}-\mathrm{O}-\mathrm{C}_{6} \mathrm{H}_{6}- \\
\mathrm{CH}_{2}-\mathrm{CH}_{-}-\mathrm{CH}_{2}-\mathrm{O}-\mathrm{C}_{6} \mathrm{H}_{6} \\
\mathrm{O}-\mathrm{CH}_{2}-\mathrm{CH}_{-}-\mathrm{CH}_{2}-\mathrm{O}-\mathrm{C}_{6} \mathrm{H}_{6}- \\
\quad \mathrm{OH}
\end{array}
\end{aligned}
$$

Scheme 2: The reaction mechanism of amine with oxirane ring.

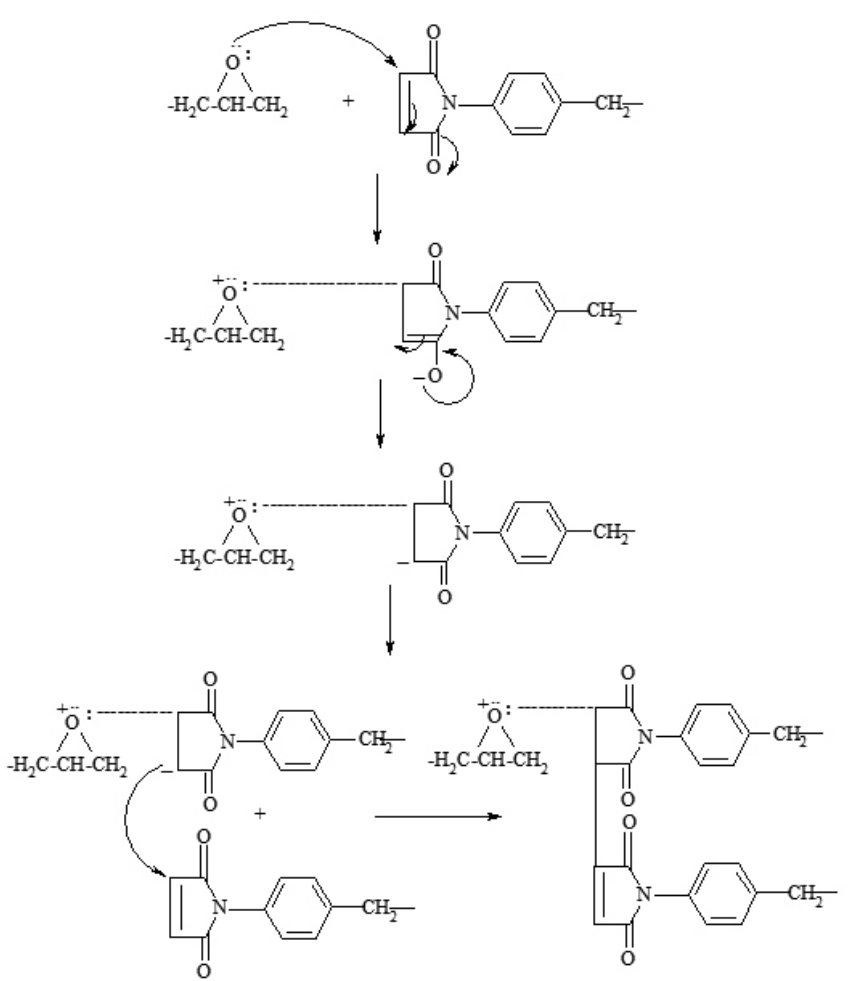

Scheme 3: Self-addition reaction of maleimide groups of maleimide epoxy compound. 


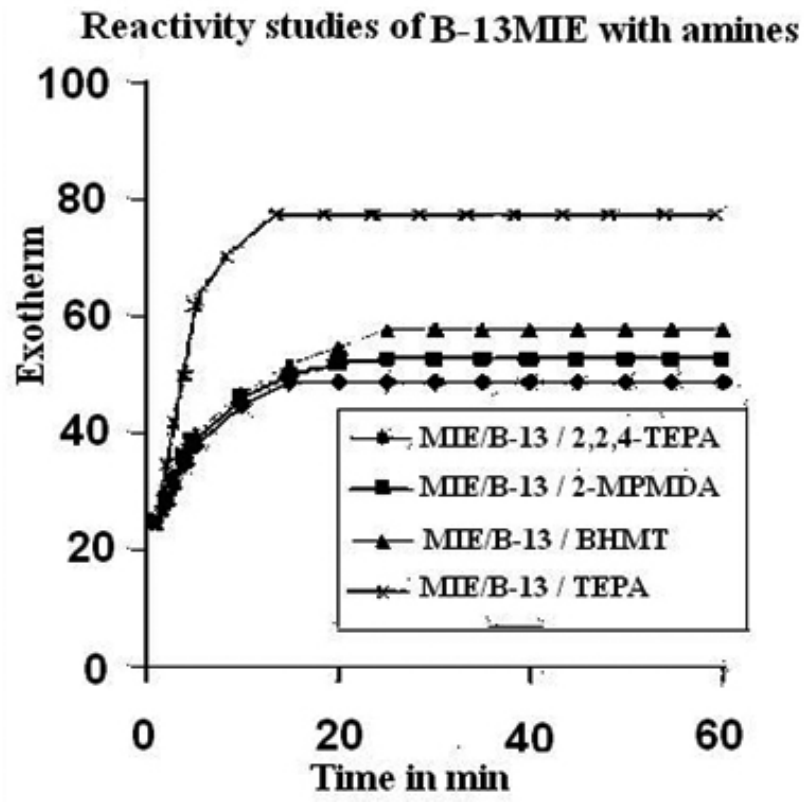

Fig 1: Reactivity studies of B-13MIE with amines at room temperature.

The high reactivity of tetraethylenepentamine (TEPA) in these series of amines studied is due to the presence of five amine groups. Bishexamethylenetriamine (BHMT) which contains three amine group showed slightly less reactivity with epoxy compared tetraethylenepentamine (TEPA). The other two amines, namely pentamethylenediamine (2-MPMDA) and 2,2,4-trimethy diamines (2,2,4-TMDA) having only two amine groups are present, least reactive compared to other two amines. This is because of the increase in electron density of the chain as the number of amino groups increase and thereby enhances the rate of polymerization. Hence, the overall reactivity was found to be in the order: TEPA $>$ BHMT $>2$-MPMDA and 2,2,4-TMDA.

Thermal properties of the cured epoxy compound: The thermal stability of the cured maleimide epoxy compound were investigated with thermogravimetric analysis (TGA) in air atmosphere. The thermograms of the cured maleimide epoxy compounds clearly indicate that the thermal stability of cured systems were improved with the incorporation of maleimide groups. ${ }^{16-19}$ With the incorporation of the maleimide groups, the IDT of the cured epoxy system was increased (Table 1). The enhancement due to incorporation of maleimide groups on the thermal stability of cured epoxy systems was thus demonstrated. On the other hand, The IPDT also systematically increased with incorporation of maleimide groups. The high IPDT (Table 1) of the maleimide-modified epoxy compound indicate high thermal stability for the cured maleimide epoxy compounds compared to traditional epoxy amine cured systems.

Table 1: Curing conditions and thermal stability of cured systems. (Evalution with TGA and DSC under air atmosphere.)

\begin{tabular}{|c|c|c|c|c|c|c|}
\hline \multirow{2}{*}{$\begin{array}{c}\text { Sl. } \\
\text { No }\end{array}$} & \multirow{2}{*}{ System } & \multirow{2}{*}{$\begin{array}{c}\text { Curing } \\
\text { conditions }\end{array}$} & \multicolumn{2}{|c|}{$\begin{array}{c}\text { Thermal } \\
\text { stability }\end{array}$} & \multicolumn{2}{|c|}{ DSC data } \\
\cline { 4 - 7 } & & $\begin{array}{c}\text { IDT } \\
{ }^{\circ} \mathrm{C}\end{array}$ & $\begin{array}{c}\text { IPDT } \\
{ }^{\circ} \mathrm{C}\end{array}$ & $\begin{array}{c}\mathrm{T}_{\text {endo }} \\
{ }^{\circ} \mathrm{C}\end{array}$ & $\mathrm{T}_{\text {exo }}{ }^{\circ} \mathrm{C}$ \\
\hline 1 & $\begin{array}{c}\text { B-13MIE } \\
/ \text { TEPA }\end{array}$ & $60{ }^{\circ} \mathrm{C}(24 \mathrm{~h})$ & 290 & 410 & 85 & 350 \\
\hline 2 & $\begin{array}{c}\text { B-13MIE } \\
/ \text { BHMT }\end{array}$ & $60{ }^{\circ} \mathrm{C}(24 \mathrm{~h})$ & 285 & 400 & 82 & 345 \\
\hline 3 & $\begin{array}{c}\text { B-13MIE } \\
/ 2-\text { MPMDA }\end{array}$ & $60{ }^{\circ} \mathrm{C}(24 \mathrm{~h})$ & 275 & 380 & 80 & 335 \\
\hline 4 & $\begin{array}{c}\text { B-13MIE } \\
/ 2,2,4- \\
\mathrm{TMDA}\end{array}$ & $60{ }^{\circ} \mathrm{C}(24 \mathrm{~h})$ & 275 & 375 & 80 & 339 \\
\hline
\end{tabular}

Differential Scanning Calorimetric Studies : From the date it is clear that the cured systems melt at $70{ }^{\circ} \mathrm{C}$ and at around $270{ }^{\circ} \mathrm{C}$ the curing reaction starts with a maximum of the exothermic peak at around $310-350^{\circ} \mathrm{C}$ (Table 1). At about $380^{\circ} \mathrm{C}$, the curing is complete where the absence of exotherm indicates no post cure.

Morphology Studies of cured systems: The morphology of fracture surfaces of cured MIEB-13 compound with amines (TEPA, BHMT, 2-MPMDA and 2,2,4-TMDA) were examined using scanning electron microscopy. (Fig 3). All the below mentioned four systems exhibits similar morphology. From the figures it is clear that the fracture surfaces of the MIEB-13 compounds with amines exhibit a homogenity material. All the cured samples exhibit similar homogeneous network in the cured samples and show no formation of distinct domains, confirming the formation of a homogeneous network in all the cured systems.

Water absorption and Chemical resistance measurements: The cured samples were cut into small specimens of $50 \times 50 \mathrm{~mm}$ and edges of specimens were coated with the same matrix system in order to avoid the Water absorption through cut edges by capillary action. All the specimens were weighed bone dry in Sartorious balance. To start with, the initial weights were noted at room temperature ${ }^{14-18}$. The samples were then immersed in water/alkali/solvent/acid for different intervals of time at room temperature, and then taken out, wiped, and dried with tissue paper, and weighed. The $\%$ water absorbed was calculated by measuring the weights of the specimen periodically using the following equation.

(Specimen weight at any time- Weight of the dry specimen) $\%$ Abs. $=$

Weight of the dry specimen. X 100

The plots of water absorption vs. square root of time were constructed to note the saturation limits of the absorbed water.

The plots of water absorption vs. square root of time were constructed (Fig 2) to note the saturation limits of the absorbed water. From the figures it is observed that initially the water uptake increased, and showed a flat profile exhibiting Fickean type behaviour ${ }^{14-16}$. The maximum water absorption under a given condition of temperature in case of cured maleimide epoxy compound with our amine systems showed a decreasing trend. Similar behavior was observed in case of acid/solvent/alkali resistance measurements (Fig 2). The maximum water/acid/alkali/solvent resistance content under a given condition of temperature in case for cured maleimide epoxy compounds with our amine systems are shown in the Table 2 . These data clearly indicate that the cured maleimide epoxy compounds with the curing agents such as Tetraethylenepentamine (TEPA), Bishexamethylenetriamine (BHMT), 2-methyl pentamethylenediamine (2-MPMDA) and 2,2,4-trimethy diamines (2,2,4-TMDA) show more resistance to water absorption and other chemicals compared to the traditional epoxy cured resin with the same amines ${ }^{20-24}$.

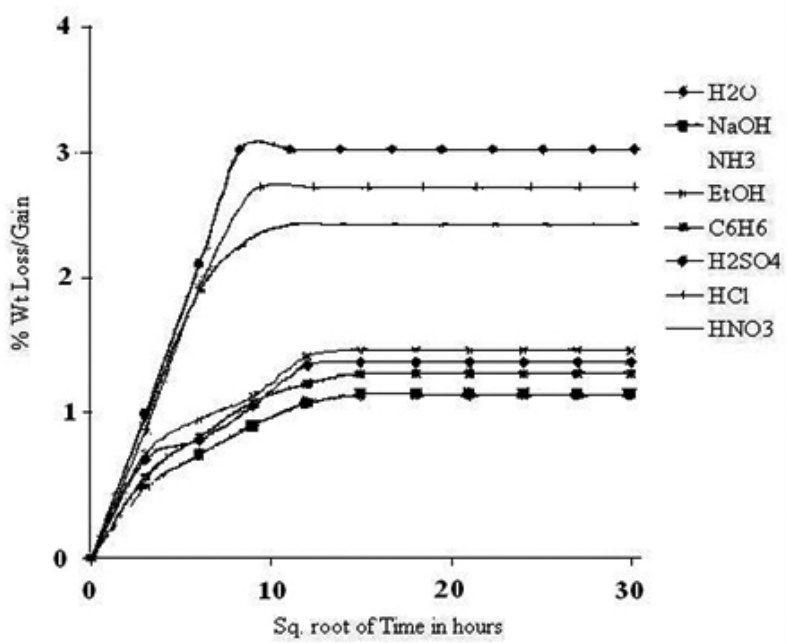

Fig 2: Water/Acid/Alkali/Solvent resistance of MIEB-13 with TEPA. 


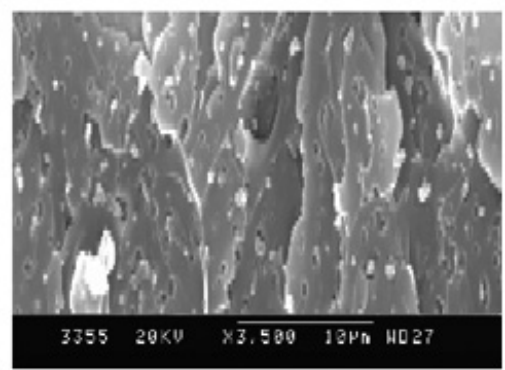

MIEB-13/TEPA

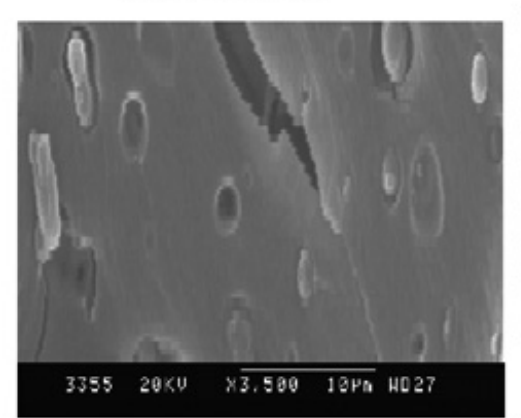

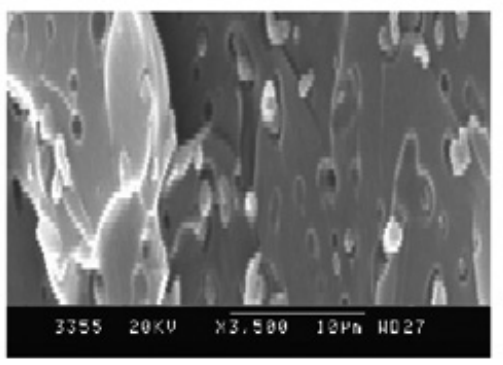

MIE B-13/BHMT

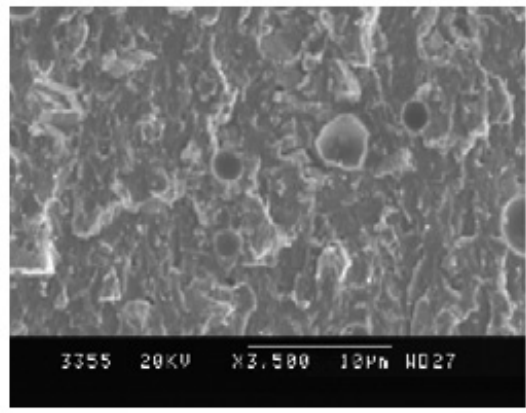

Fig 3: Fractured morphology analysis of cured maleimide epoxy compound with different amines.

Table 2: The maximum water absorption/acid/alkali/solvent resistance under a given condition of temperature $\left(25^{\circ} \mathrm{C}\right)$.

\begin{tabular}{|c|c|c|c|c|c|c|c|c|c|}
\hline \multirow[b]{2}{*}{$\begin{array}{l}\text { Sl. } \\
\text { No }\end{array}$} & \multirow[b]{2}{*}{ System } & \multicolumn{5}{|c|}{$\%$ Weight Gain } & \multicolumn{3}{|c|}{$\%$ Weight loss } \\
\hline & & $\mathrm{H}_{2} \mathrm{O}$ & $\begin{array}{c}10 \% \\
\mathrm{NaOH}\end{array}$ & $\mathrm{NH}_{3}$ & $\mathrm{C}_{2} \mathrm{H}_{5} \mathrm{OH}$ & $\mathrm{C}_{6} \mathrm{H}_{6}$ & $\mathrm{H} 2 \mathrm{SO}_{4}$ & $\mathrm{HCl}$ & $\mathrm{HNO}_{3}$ \\
\hline 1 & $\begin{array}{l}\text { B-13MIE } \\
\text { / TEPA }\end{array}$ & 1.70 & 1.52 & 1.45 & 1.79 & 1.58 & 3.80 & 3.55 & 3.70 \\
\hline 2 & $\begin{array}{l}\text { B-13MIE } \\
\text { / BHMT }\end{array}$ & 1.75 & 1.63 & 1.50 & 1.80 & 1.68 & 3.90 & 3.72 & 3.80 \\
\hline 3 & $\begin{array}{l}\text { B-13MIE } \\
\text { /2-MPMDA }\end{array}$ & 1.90 & 1.75 & 1.72 & 1.95 & 1.69 & 3.90 & 3.80 & 3.90 \\
\hline 4 & $\begin{array}{c}\text { B-13MIE } \\
/ 2,2,4-\mathrm{TMDA}\end{array}$ & 1.91 & 1.79 & 1.85 & 1.98 & 1.71 & 3.90 & 3.85 & 3.90 \\
\hline
\end{tabular}

\section{CONCLUSION}

The thermally cured maleimide epoxy (MIE) compounds with aliphatic long chained amines such as Tetraethylenepentamine (TEPA), Bishexamethylenetriamine (BHMT), 2-methyl pentamethylenediamine (2-MPMDA) and 2,2,4-trimethy diamines (2,2,4-TMDA) exhibited excellent thermal stability and good chemical (acid/alkali/solvent) and water absorption resistance with homogeneity in their morphology.

\section{REFERENCES}

1. R. R. Jones. In: Ellis. B. Editor. London/ Chapman\&Hall. 8 (1993).

2. J. N. Hay. B. Woodfine. M. Davies. High Perporm Polym. 35 (1996).

3. Ishikawa.S. Nakatani. M. Fukuda.H and Yamamoto, S. Jpn Patent .8 (1996).

4. T. Agag and T. Takeichi.. Polymer. 40 (1999).

5. K. Gaw, M. Kikei. M.Kakimoto. and Y. Imai. Polymer. 38 (1997).

6. W.G, Kim . T.Y, Nam. J Polym Sci. Part A:Poly Chem. 34 (1996).

7. S. J, Park. H.C, Kim. H.I Lee, and D.H. Suh. Macromolecules. 43(2001).

8. A. A Kumar. M Alagar. and RMVGK. Rao. Polymer. 43 (2002).

9. P. Musto. E Martuscelli.G. Ragosta. and G. Scarinzi. J Appl polm Sci. 69 (1998).
10. A. A Kumar. M Alagar. and RMVGK.Rao. J Appl Polym Sci. 81(2001).

11. A.A Kumar. M Alagar. and RMVGK.Rao.J Appl Polym Sci. 83 (2001).

12. J. L, Han. Y.C.Chen. K.Y.Li. and K.H.Hsieh. J Appl Polym Sci. 70(1998).

13. YL.Liu Liu YL. Jeng R.J.Chiu J Polym Sci, Part A. Polym Chem. 56 (2001).

14. K.N. Shivananda. and K.N. Mahendra. Bull. Korean. Chem. Soc, 27 (2006).

15. Shivananda K.N.and Mahendra. K.N..Ira. Polymer Journal, May 16(3) (2007).

16. L.A.White. W.J. Weber. and L.Mathias. J. Polym Bull. 46 (2001).

17. T.Shibora. S.Okuse. T.Aoki. and H.Kato. US Patent. 6 (2000).

18. A. Vanaja. Ph.D Thesis. Bangalore University. Bangalore. (2003).

19. Wu. Chuan-Shao. Ying-Ling Liu. and Keh-Ying Hsu. Polymer. 44 (2003).

20. W.R. Ashcroft. In: B. Ellies. Editor. Chapman and Hall. 2 (1993).

21. Y.L.Liu. R.J.Jeng. and Y.S. Chiu. J.Poly Sci.Part-A. 39 (2001).

22. K.N.Shivananda. and K.N. Mahendra. Int.Congress of Chemistry and Env. 2 (2005).

23. C.H.Vinod Kumar, K.N. Shivananda, R.V, Jagadeesh. C. Nagaraju, J. of Molecular Catalysis A: Chemical, Vol. 311, 1-2, 15, P-23-28, 2009.

24. K.N.Shivananda, R.V.Jagadeesh, Puttaswamy, K.N. Mahendra. J. of Molecular Catalysis A. Chemical. 255 (2006). 